\title{
Design on College Japanese Online Examination System Based on UML
}

\author{
Yun Jiang \\ College of Foreign Languages, Bohai University, Jinzhou, 121013, China \\ 593538995@qq.com
}

Keywords: UML; college Japanese; examination system; function design; database design

\begin{abstract}
Examination has been an indispensable part of the education process, with the increasing number of College Japanese test, the design of online examination system is very important. This paper is based on the UML technology to design the Japanese examination system. First, study of Japanese education reform and the development of Japanese teaching needs; then, using UML to carry on the examination system use case analysis, including the system use case diagram and class diagram; next, module structure design and describes the functions of each module; finally, database design of the system, including conceptual design and logical structure design. The successful application of this system to solve the drawbacks of traditional paper exams, and it will play a positive role in improving the management information level and Japanese teaching level.
\end{abstract}

\section{Introduction}

With the gradual deepening of higher education reform, private education institutions has increased year by year, the booming development of Sino-Japanese trade exchange as well as the social demand increasingly for professionals talents in Japanese, for China's College Japanese test proposed new requirements, implementation of education reform in college major Japanese exam without delay. The current "College Japanese Teaching Syllabus" provides teaching purposes of College Japanese [1]: cultivate students with strong reading skills, some translation capability, listening and speaking ability, initial writing skills, so that students can use Japanese as their tool access to information needed for professional and lay a good foundation for further improving Japanese. Most of the conventional exam is multiple choice objective questions, but the kinds of questions a single do not pay attention to exercise practical application of language skills. Therefore, the effective implementation of the college Japanese examination system for the implementation of the Japanese Language Syllabus, improve the quality of college Japanese teaching and the level of students Japanese have played a crucial role. This article in Japanese examination systems exam questions are divided into: listening comprehension, word usage, grammar structure, and Chinese translates Japanese, Japanese translates Chinese, reading comprehension and writing. This paper designs the system based on UML.

UML combines the advantages of many object-oriented modeling languages, and it plays a very important role for project development and team communication in the analysis and design of the system. Although it will take a certain time in the analysis and design, it will improve the accuracy and efficiency of encoding, and form a simple, consistent and common object-oriented modeling language [2]. During the development of the software system, the UML can be used in the whole design cycle, to help designers shorten design time, reduce the cost of the improvement, and make the best software and hardware partition.

\section{UML Technology}

UML (Unified Modeling Language) is a standard graphical modeling language, which is the standard representation of object-oriented analysis and design, said it is to bring the essence from a variety of object-oriented modeling technology and developed, and became the object-oriented modeling language industry standard [3]. Used to describe software, visualization, construction and building software systems product documentation. It records the decisions and understanding of the 
system must be constructed, which can be used to understand, design, browse, configure, maintain and control information for the system.

UML is the most widely used tool to use object-oriented techniques, for all the steps of object-oriented development methods have provided strong support. UML is very powerful, it can be used to describe software systems to help build accurate, unambiguous and complete model; unified pre-defined symbols visually represent software systems, unambiguously interpreted by another developer writes the model; construct and all sorts of different programming languages directly communication software system model and directly generate code framework: the development and deployment phase, according to the expression of system demand to make the software system model documentation [4]. In each step, mainly get results are the use-case model, analysis model (including static and dynamic models), design models (including static and dynamic models), object-oriented code and object-oriented test cases and other achievements. UML standard does not define a standard development process, but it applies to iterative development process. It is designed to support most of the existing object-oriented development process.

Typically UML concepts and models can be divided into static structure and dynamic behavior, implementation structure, model organization and expansion mechanism. As a modeling language, UML contains two meanings: one is the semantic meaning, and the other is a visual expression method. UML is mainly abstract on the basis of the various models elements of the three kinds of model defined, and propose a standard specification on the basis of their representation. It is only a standard language for describing the model, although the basic concepts permeate many methodology, but did not give a complete methodological guide in the standard.UML is a kind of standard, graph is one of the most important form of expression.。

\section{Use Case Analysis of Examination System}

The use of UML for system analysis, it is to use oriented object method to analyze the system, in order to establish the object oriented system model, this paper mainly adopts UML use case diagram, class diagram to the examination system demand to carry on the analysis, and to establish use case model. Help developers understand the system functions and system process analysis [5-6].

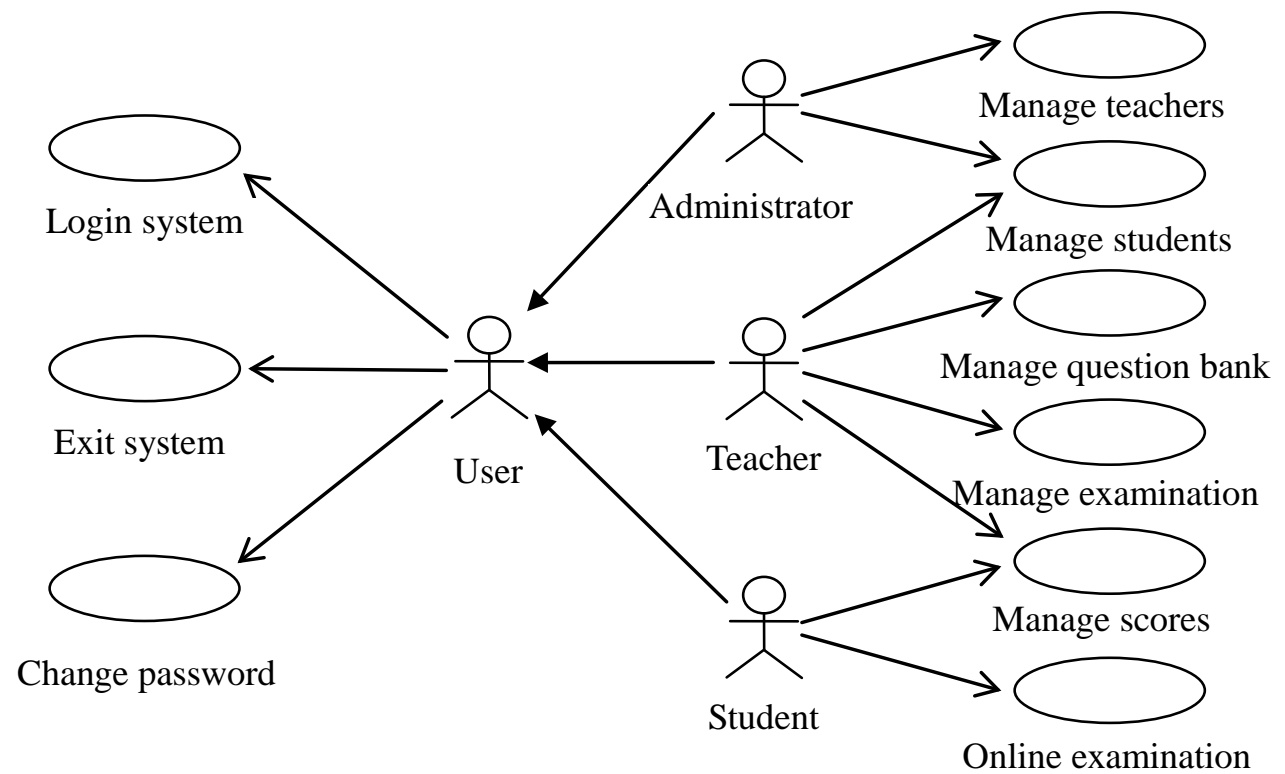

Fig. 1. Use case diagram of online examination system

Use case diagram is used to describe the using process of the system. It is can intuitively expression specific functions of each module of the system and their object-oriented. Use case diagrams to describe the system's functions and demand from the user's perspective, to show the various types of roles outside the system and the relationship between the system internal use cases. The so-called use case refers to a description of the system function (or the system use), actors are those who might use these use cases or external systems, and the link between the two describes 
"who use which use case" [7]. Thus, the use case diagram focused on from the system external actors' perspective to describe the system needs to provide what function, and indicates the person who performs these functions is. To determine the use case of system in accordance with various roles within the system need to complete the transaction. Function of the online examination system based on different user roles are divided into: administrators, students and teachers. System use case diagram is shown in Fig. 1; respectively denote the administrators, teachers and students can engage in activities: Administrators can engage in activities, including login and exit the system, manage teachers and students information; teachers can engaged in activities, including manage student information, manage exam question (including add, modify, delete exam question), manage the exam (query exam situation, scores); students can engage in activities, including online exam, the query scores.

Create the system class diagram, mainly by finding classes and objects and the relationships between them, namely: first need to identify the objects in the system, and further abstract class from the object, and then define the internal characteristics of the class, and finally found external relations of the class. It is a description of the system static structure model. The model elements that are allowed in the class diagram are only classes and the relationship between classes and classes. The online examination class diagram of this paper is shown in Fig. 2.

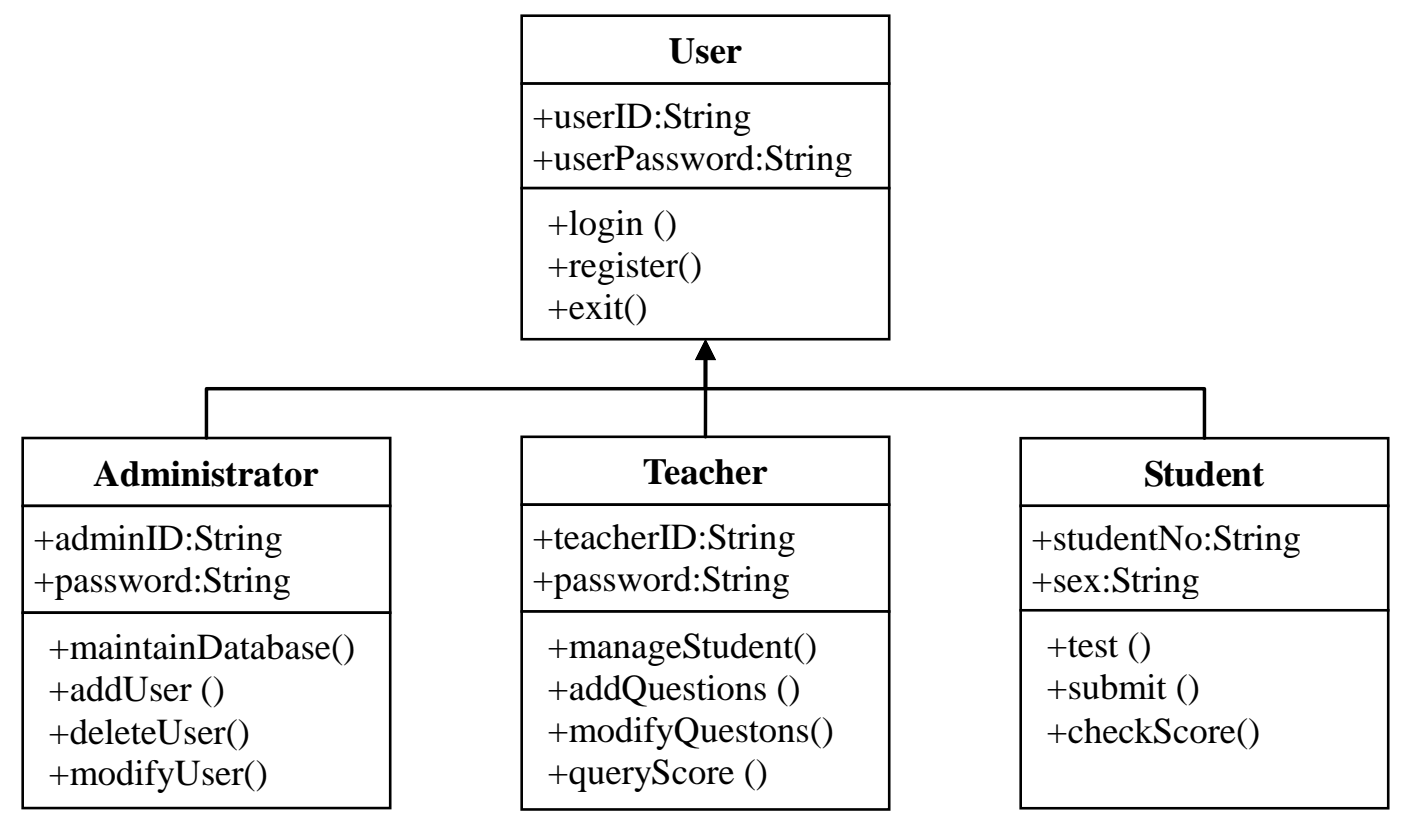

Fig. 2. Class diagram of online examination system

\section{Function Module Design}

According to the actual needs of the teaching and management of Japanese language courses, the online examination system is designed. The user of the system is including students, teachers and administrators. The main modules include the Japanese language questions bank, test paper management, online examination, information management and system maintenance, and so on. Functional simulation is briefly described as follows:

Japanese questions bank modules: teachers manages exam questions types and question bank, and maintenance, including entry, query, modify and delete functions; test paper management module for teachers to achieve papers create, view, edit, print and delete functions, test paper generating functions include random question papers generated and manually topic papers generated in two ways [8]; online examination module provides students with online exam, and candidates log into system, can get the papers into browser interface, the system prompts until student can answer the exam begins, the end of the examination time automatic submitting test paper. And students in the papers submitted directly give a score, as well as reference to the answer can be checked, it can at any time to reflect student learning, and timely feedback test case, for the 
students to further learn Indicate the specified direction, and help students to improve learning methods. Information management and maintenance module, main function is: administrators to manage student and teacher information, and system maintenance.

\section{Database Design}

Design science's database is an important component module of online examination system, which is primarily responsible for storing the entity information of data [9]. And it is core technology modules in the design and development of the online examination system, how to build a good database table structure, to improve the efficiency of data storage for systems, and ensure the consistency and integrity of data. Whether the each function modules of the online examination system can be closely integrated and how to combine, the key lies in the database. Database design quality directly affects the data redundancy in the database, consistency and other issues. There will also be conducive to the development and implementation of programs. User needs is embodied in a variety of information provided, save, update and query, which requires the database structure to meet all kinds of information input and output, in the system carried on the comprehensive analysis and on the basis of the current examination system database reference, the database design of online examination system will from the database concept design and logical structure design in two stages, to describe separately for the database design of the system.

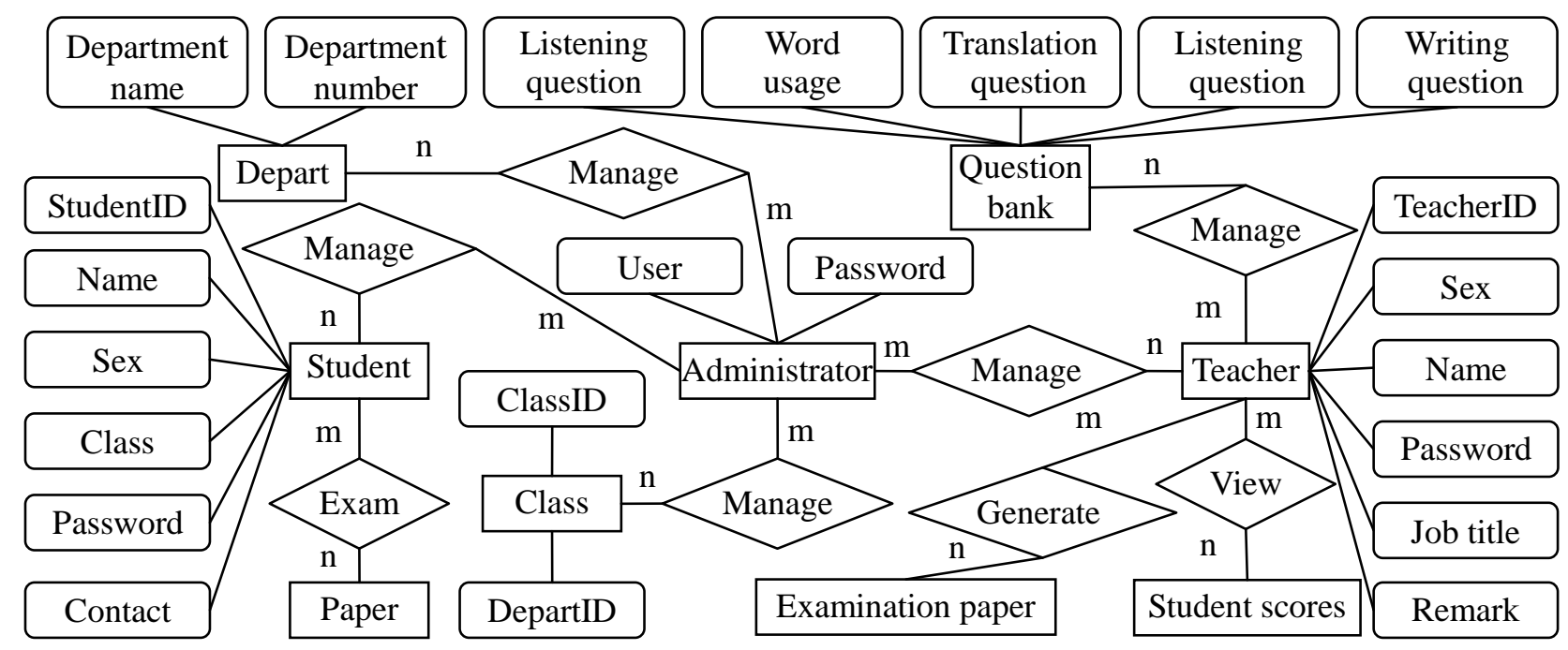

Fig. 3. E-R diagram of the system

Conceptual structure design of the database is primarily to the user' needs of demand analysis phase abstract conceptual model of information world, using the bottom-up approach for concept design of system, through the analysis of the data and data structure for the examination system, and abstract the conceptual model of the reality world, the principal entity of online exam system can be established: administrator, teacher, exam question, students, and briefly devised E-R diagrams, lay the foundation for the logical design of the database. E-R diagram of the system is shown in Fig. 3.

The logical structure design: the conceptual structure of the data model converted to actual model of SQL database systems, the entity-relationship model (E-R diagram) is derived from the conceptual design into the relational schema, specifically as follows, to obtain the logical structure of the database, and can set up tables structure in the database system, the main tables in the database are: administrator information table, teacher information table, student information table, exam question bank information table, exam paper information table, scores information table and other tables, which the exam paper table is shown in Table 1 :

\section{Conclusion}

With Japanese hot and the continuous rich Japanese education content, increasing number of 
people to take the Japanese test, requires online examination system to continue to upgrade, enhancements, and can be a good solution to the problem of overloading when traffic caused by a high concentration. Therefore, the establishment of a highly scalable, flexible, stable and scalable and easy to maintain in the Japanese online examination system is an important part of the development of education. In the past, manual marking test paper caused great waste of time and manpower, and low efficiency. This article designs college Japanese online examination system based on UML, promote the further the further improvement of the Japanese examination and teaching, which can regulate Japanese network online examinations, scientific run network examination system. At the same time, it can enrich and improve the Japanese teaching system, which has laid a favorable foundation for the reform of the Japanese teaching content and teaching methods. Finally, it can reflect the teacher's teaching situation in time, and provide a reliable basis for further enhance and improve teaching methods.

Table 1. Examination Paper Information Table

\begin{tabular}{c|l|c|c|c|l|c|c}
\hline No & Field name & Data type & Byte & No & Field name & Data type & Byte \\
\hline 1 & ExaminationPaperNo & Int & 10 & 10 & TranslationNumber & Varchar & 10 \\
\hline 2 & WordNumber & Varchar & 10 & 11 & TranslationScore & Int & 10 \\
\hline 3 & WordScore & Int & 10 & 12 & WritingNumber & Varchar & 10 \\
\hline 4 & ReadingNumber & Varchar & 10 & 13 & WritingScore & Int & 10 \\
\hline 5 & ReadingScore & Int & 10 & 14 & TotalScore & Int & 10 \\
\hline 6 & GrammarNumber & Varchar & 10 & 15 & TestTime & Int & 10 \\
\hline 7 & GrammarScore & Int & 10 & 16 & DifficultyFactor & Int & 10 \\
\hline 8 & ListeningNumber & Varchar & 10 & 17 & SetupDate & Datetime & 8 \\
\hline 9 & ListeningScore & Int & 10 & 18 & Remarks & Text & 10 \\
\hline
\end{tabular}

\section{References}

[1] H. F. Wei, "An analysis of the four levels of Japanese Professional Test and Teaching in College," Journal of Kaifeng Education Institute, vol. 34, no. 9, pp. 91-92, 2014.

[2]

$$
\text { Baidu Encyclopedia, }
$$

"UML,"

http://baike.baidu.com/view/174909.htm?fromtitle=UML\&fromid=446747\&type=syn, 2015-7-15.

[3] Q. Niu, "The Design and Analysis of System of Programming Testing based on UML," Master's degree of Xi'an Electronic and Science University, 2010.

[4] X. C.Deng, "Design and Implementation of Online Examination System based on UML," Master's degree of Zhejiang University of Technology, 2012.

[5] G. Y.Sun, "Design and Implementation of Online Examination System based on B/S," Master's degree of Jilin University, 2014.

[6] T. Wang, "Design and Implementation of Online Examination System based on UML," Master's degree of Shandong Normal University, 2014.

[7] Y. Q. Tang. Y. Q. Song, "Analysis and Design of Computer Examination System based on UML," Information Technology and Informatization, vol. 40, no. 4, pp. 27-28, 2015.

[8] S. Y. Teng, "Design and Development of a Network of English Examination System," Journal of Changchun Education Institute, vol. 29, no. 11, pp. 41-47, 2013.

[9] L. Gong, "Online Testing System Database Design and Architecture," Information \& Communications, vol. 29, no. 3, pp. 114-115, 2015. 